\title{
Attachment, validation, and preliminary deployment of ultrasonic heart rate transmitters on largemouth bass, Micropterus salmoides
}

\author{
Steven J. Cooke ${ }^{\mathrm{a}, *}$, Christopher M. Bunt ${ }^{\mathrm{b}}$, Jason F. Schreer ${ }^{\mathrm{c}}$, David P. Philipp ${ }^{\text {a }}$ \\ ${ }^{a}$ Department of Natural Resources and Environmental Sciences, University of Illinois and Center for Aquatic Ecology, Illinois Natural History Survey, \\ 607 E. Peabody Dr., Champaign, Illinois, 61820, USA \\ ${ }^{\mathrm{b}}$ School of Marine Biology and Aquaculture, James Cook University, Townsville, 4811, Australia \\ ${ }^{\mathrm{c}}$ Department of Biology, University of Waterloo, Waterloo, Ontario, N2L 3G1, Canada
}

Received 16 January 2002; accepted 14 March 2002

\begin{abstract}
Although there are numerous published accounts of studies utilizing heart rate $(f \mathrm{H})$ transmitters in fish, few of these studies provide sufficient detail to aid other researchers in deploying these devices. Here, we detail the attachment, validation, and preliminary deployment of a commercially available ultrasonic $f \mathrm{H}$ transmitter. We used largemouth bass, Micropterus salmoides, for this study because they principally modulate cardiac output using $f \mathrm{H}$, making them logical candidates for this technology. Using an external harness that balanced the battery on one side of the dorsum, and the transmitter on the other, we attached the device to 13 fish. Electrodes were positioned ventral-laterally to the pericardial cavity. Doppler flow probes were used to validate that the transmitter was detecting and emitting a signal when triggered by the depolarization of the ventricle (QRS wave), as indicated by peaks in blood flow. We then deployed the $f H$ transmitters for periods of up to 32 days, generating one of the most complete series of $f \mathrm{H}$ data available. We present preliminary data illustrating the information available from $f \mathrm{H}$ transmitters at different temporal resolutions (real time vs. hourly means), including relationship of $f \mathrm{H}$ to temperature, behavioral correlates of $f \mathrm{H}$, and diel patterns of $f \mathrm{H}$. (c) 2002 Ifremer/CNRS/Inra/IRD/Cemagref/Éditions scientifiques et médicales Elsevier SAS. All rights reserved.
\end{abstract}

\section{Résumé}

Mise en place, validation et première mise en ouvre d'émetteurs cardiaques ultrasoniques chez l'achigan à grande bouche Micropterus salmoides. Bien que de nombreuses études rapportent l'utilisation d'émetteurs permettant la télémesure de la fréquence cardiaque $(f C)$ chez les poissons, peu d'études donnent suffisamment de détails pour permettre une mise en œuvre rapide de cette technique. Nous détaillons ici une méthode de marquage, une procédure de validation, et la mise en œuvre d'un émetteur ultrasonique $f C$ disponible dans le commerce. Pour cette étude, nous avons utilisé Micropterus salmoides, en raison de la capacité de cette espèce à moduler son débit cardiaque via la régulation du rythme de ces battements cardiaques $(f \mathrm{C})$. Treize individus ont été équipés d'un harnais dorsal, la batterie et l'émetteur étant placés de part et d'autre de la nageoire dorsale. Les électrodes sont placées ventro-latéralement à proximité de la cavité péricardique. L'utilisation de sondes à effet Doppler a permis de vérifier que l'émission ultrasonore de l'émetteur correspondait à la contraction ventriculaire (onde QRS). La fréquence cardiaque des animaux appareillés a été enregistrée durant des périodes allant jusqu'à 32 jours, générant ainsi l'une des séries temporelles les plus complètes actuellement disponibles. Nous présentons ici ces données préliminaires qui illustrent les informations obtenues, à différentes résolutions temporelles (en temps réel, moyennes horaires), ainsi que les relations entre $f C$ et la température, le comportement et ou le cycle journalier d'activité. (C) 2002 Ifremer/CNRS/Inra/Cemagref/Éditions scientifiques et médicales Elsevier SAS. Tous droits réservés.

Keywords: Heart rate; Telemetry; Attachment; Largemouth bass; Methodology

\footnotetext{
* Corresponding author.

E-mail address: scooke@uiuc.edu (S.J. Cooke).
} 


\section{Introduction}

Heart rate $(f \mathrm{H})$ is a robust indicator of stress in many species and has been used to document responses to different husbandry conditions (Rabben and Furevik, 1993), environmental conditions (Claireaux et al., 1995; Lefrançois et al., 1998), and human-induced disturbances (Anderson et al., 1998). Heart rate can also be used to estimate metabolic rate in free-swimming fish for establishing field energetics models and to ascribe costs to different activities or perturbations (Priede, 1983; Armstrong, 1998). Studies collecting telemetered $f \mathrm{H}$ signals from free-swimming fish were first conducted over 30 years ago.

Recent studies have criticized the use of $f \mathrm{H}$ telemetry for estimating metabolic rate because of the weak and variable relationship between $f \mathrm{H}$ and oxygen consumption (Thorarensen et al., 1996). This criticism reflects the repeated (and continued) use of $f \mathrm{H}$ transmitters for estimating field energetics of fish species that are not cardiac frequency modulators (e.g., salmonids; Farrell, 1991). As more species are found to be cardiac frequency modulators (e.g., Schreer et al., 2001), opportunities for employing $f \mathrm{H}$ telemetry for the study of field metabolic rates may also be legitimized. Indeed, northern pike, Esox lucius, apparently the only cardiac frequency modulator discussed by Thorarensen et al. (1996), was acknowledged as the best candidate for $f \mathrm{H}$ telemetry to date (see Lucas et al., 1991; Armstrong, 1998).

Our laboratories have been studying the cardiac function and swimming energetics of temperate teleost fish species and have discovered that cardiac frequency modulation is more widespread than once thought (see Farrell, 1991). Several of the fish species that we have investigated in the lab within the family Centrarchidae appear to regulate cardiac output principally through changes in $f \mathrm{H}$ when exposed to a multitude of different conditions (i.e., swimming, exhaustive exercise, temperature change, hypoxia) (Schreer et al., 2001; Schreer and Cooke, in press; Cooke and Philipp, unpublished data). Based upon these preliminary findings, we felt it opportunistic to attempt to develop approaches for measuring $f \mathrm{H}$, and eventually estimating metabolic rate in free-swimming largemouth bass, $\mathrm{Mi}$ cropterus salmoides, a cardiac frequency modulator (Cooke, unpublished data).

When we began to experiment with $f \mathrm{H}$ transmitters, it quickly became evident that previously published methodologies were lacking in detail. In many cases, the type and size of transmitter, number of study animals, and duration of monitoring were cryptic or not reported at all. Furthermore, there was typically little, if any information on the configuration of the transmitter, including the important electrodes and the attachment or implantation techniques. The morphological characteristics of the fish, expected habitat use, and other experimental factors require that some degree of customization is required for most applications. To our knowledge, there have also been no reports of the simultaneous monitoring of signals from $f \mathrm{H}$ transmitters and either electrocardiograms (ECG) or Doppler flow probes to validate that the $f \mathrm{H}$ transmitters are functioning properly. As a result, here we outline our customization of a commercially available transmitter, detail the attachment technique, and validate that the transmitter is functioning properly. Finally, we provide a brief overview of our successes (... and failures) thus far, by presenting some preliminary data from our initial deployments.

\section{Materials and methods}

\section{1. fH Transmitters and Receiving System}

We used a commercially available pulse-triggered ultrasonic $f \mathrm{H}$ transmitter (V16H-4HR, Vemco Inc, Shad Bay, NS) that weighed $30 \mathrm{~g}$ in air and measured $16 \times 72 \mathrm{~mm}$. Detailed description of the functioning of the transmitter may be found elsewhere (Claireaux et al., 1995; Vemco, 1995). We constructed our own battery packages (3.6 V) of two sizes (small, 1/2 AA, lithium, $15 \times 25 \mathrm{~mm}, 8 \mathrm{~g}$ in air, $950 \mathrm{mAh}$; large, AA, lithium, $15 \times 51 \mathrm{~mm}, 16 \mathrm{~g}$ in air, 2100 $\mathrm{mAh})$. Their use depended upon the mass of the fish and the desired monitoring duration ( $\sim 15$ days, small, or $\sim 35$ days, larger). Wires (20 G Generic Insulated Copper Wire) were soldered to the positive and negative battery terminals (solder tabs) and twisted together. The battery package was then waterproofed using a flexible synthetic rubber coating (Plasti Dip, Plasti Dip International, Blaine, MN). The two battery lead wires $(\sim 15 \mathrm{~cm})$ were soldered to the appropriate transmitter power inputs and then sealed with plastidip (Fig. 1).

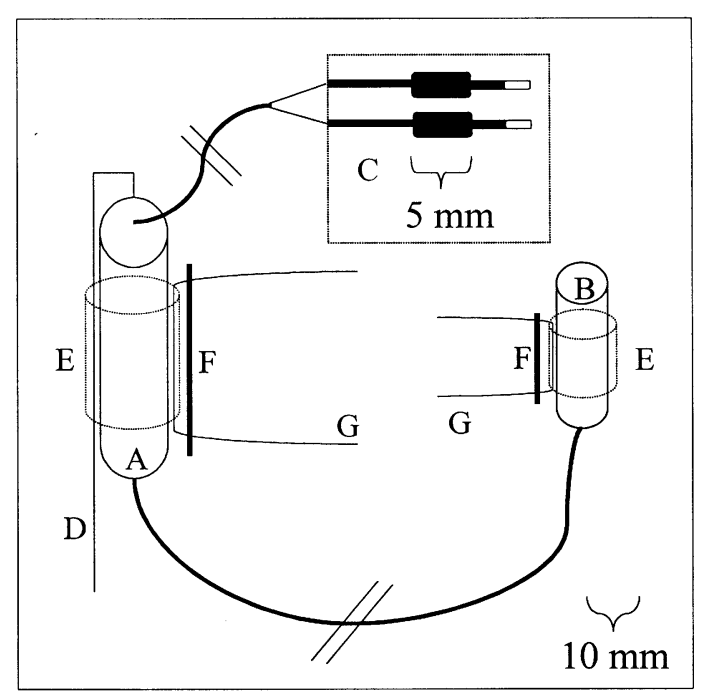

Fig. 1. Schematic of $f \mathrm{H}$ transmitter and attachment apparatus. (A) $f \mathrm{H}$ transmitter package, (B) $3.6 \mathrm{~V}$ battery pack, (C) Electrodes, black indicates insulation, white indicates gold-plating, (D) Stainless steel reference electrode, (E) Heat shrink tubing, (F) Plastic backing plate with neoprene padding, (G) Surgical stainless steel harness. Note that the inset box depicting the electrodes is at a different scale. 
The annealed surgical stainless steel electrode wires $(0.378 \mathrm{~mm}$, Willing B Wire Corp, Willingboro, NJ) were between 25 and $35 \mathrm{~cm}$ in length and were individually shielded with thin-walled teflon tubing $(0.452 \mathrm{~mm}$ ID, TFT 200, Alpha Wire Inc., Elizabeth, NJ). The electrode wires were soldered to the electrode posts on the transmitter. The distal end of the electrode wires had $5 \mathrm{~mm}$ of sheathing removed and were soldered (using silver solder) to rigid gold-plated electrodes (wire wrap 264D-M-0.6 mm $\times 40 \mathrm{~mm}$ electronic pin). The wire wrap end of the electrode was trimmed such that the length of electrodes were $16 \mathrm{~mm}$. The distal end of the electrode was rounded slightly so that it would not puncture the pericardium. The solder joint, end of the sheathing, and all but the most distal $3 \mathrm{~mm}$ of electrode were sealed and insulated with plastidip (Fig. 1). A reference electrode consisting of non-insulated annealed stainless steel wire $(0.378 \mathrm{~mm}$ diameter $\times 10 \mathrm{~cm})$ trailed beside the transmitter.

Heat shrink tubing ( $22 \mathrm{~mm}$ diameter) was used to hold a $40 \mathrm{~cm}$ length of annealed surgical stainless steel wire $(0.378 \mathrm{~mm})$ in place that served as the external attachment wires for both the transmitter package and the battery. A plastic backed piece of $2 \mathrm{~mm}$ neoprene was mounted onto each set of wires with the neoprene facing in the direction of the end of the wires. The transmitters were customized in the period between fish capture and attachment such that the electrode wire and battery leads were as short as possible.

We used a VR-60 acoustic receiver (Vemco Inc., Shad Bay, NS) with an omnidirectional hydrophone to record telemetric signals. Data were relayed via an RS - 232 port to a laptop computer. Software provided with the transmitters (VSCAN - GPS, V4.06, Vemco Inc.) was used to log data to the computer. Depending upon the number of fish tagged and our daily objectives, we were able to use the provided software to focus the receiver to scan as desired.

\subsection{Attachment}

Fish were collected from Lake Opinicon, Ontario by angling or Forbes Reservoir in Illinois by electrofishing. In Ontario, fish were held in a wet lab at the Queen's University Biological Station supplied with ambient lake water. In Illinois, fish were held at the Illinois Natural History Survey aquatic research facility supplied with ambient water from experimental ponds. Fish were held for at least 48 hours prior to surgery in flow through tanks. Fish $(\mathrm{N}=13 ;$ mean $\pm \mathrm{SE}$; total length $(\mathrm{TL})=441 \pm 11 \mathrm{~mm}$; weight $=1406 \pm 115 \mathrm{~g}$ ) (Table 1), were anaesthetized prior to surgery with $60 \mathrm{ppm}$ clove oil (emulsified with ethanol, 9:1 ethanol: clove oil). When a fish was unresponsive $(\sim 10$ min), it was positioned on the surgery table with its ventral side down. A soft wet cloth covered the eyes and a pump was used to circulate aerated water (with a maintenance dose of anesthetic; $30 \mathrm{ppm}$ clove oil) over the gills. Water was also poured over the fish at frequent intervals to keep the skin moist. The first step involved land-marking the location for the transmitter attachment (for both the transmitter package and its battery), while ensuring that the electrode wires would reach the ventral pericardial cavity. The battery and transmitter were always on opposite sides of the fish's body and were offset slightly (anteriorposteriorly) to permit attachment (Fig. 2). Two hypodermic needles (21 gauge) inserted through a piece of plastic neoprene coated backing (distance between holes adjusted to that of the transmitter wires) were inserted through the dorsal musculature in the region under the dorsal fin. When the needle projected out the other side of the fish, the surgical stainless steel wires were passed back through the fish at which time the needles were removed leaving the plastic backing plate in place. The wire was tightly twisted, pushed backward (as to not collect aquatic vegetation) and

Table 1

Largemouth bass $(n=13)$ used for heart rate telemetry studies. Tag ratio is the ratio of tag mass in water to the weight of the fish. Days represent the duration of successful monitoring. Location codes are for Queen's University Biology Station (QUBS) and the Illinois Natural History Survey Aquatic Field Laboratory (INHS).

\begin{tabular}{|c|c|c|c|c|c|c|c|c|c|}
\hline Fish Code & $\begin{array}{l}\mathrm{TL} \\
(\mathrm{mm})\end{array}$ & $\begin{array}{l}\text { Weight } \\
(\mathrm{g})\end{array}$ & $\begin{array}{l}\text { Tag Ratio } \\
(\%)\end{array}$ & Sex & Days & Location & Use & $\begin{array}{l}\text { Reason } \\
\text { For Termination }\end{array}$ & Fate \\
\hline LMB A & 363 & 720 & 3.3 & $\mathrm{~F}$ & 3 & QUBS & Pilot & Erratic Signals & Post Mortem \\
\hline LMB B & 399 & 910 & 2.6 & $\mathrm{~F}$ & 6 & QUBS & Pilot & Fungus & Post Mortem \\
\hline LMB C & 434 & 1370 & 1.7 & $\mathrm{~F}$ & 6 & QUBS & Pilot & Electrode Wire Cut & Post Mortem \\
\hline LMB D & 429 & 1190 & 2.9 & M & 32 & QUBS & Fig. 5, 6, 7 & Electrode Shift & Released \\
\hline LMB E & 432 & 1260 & 2.7 & $\mathrm{~F}$ & 13 & QUBS & Fig. 2, 5 & Fungus & Post Mortem X Ray \\
\hline LMB F & 430 & 1160 & 2.0 & M & 15 & QUBS & Fig. $3,4,5$ & Electrode $\mathrm{Shift}^{+}$ & Released \\
\hline LMB G & 468 & 1940 & 1.2 & $\mathrm{~F}$ & $4 *$ & INHS & Angling Experiment & Experiment Ended & Euthanized \\
\hline LMB H & 463 & 1910 & 1.3 & $\mathrm{~F}$ & $4 *$ & INHS & Angling Experiment & Experiment Ended & Euthanized \\
\hline LMB I & 480 & 1860 & 1.3 & M & $5 *$ & INHS & Angling Experiment & Experiment Ended & Euthanized \\
\hline LMB J & 470 & 1640 & 1.5 & M & $5 *$ & INHS & Angling Experiment & Experiment Ended & Euthanized \\
\hline LMB K & 515 & 1950 & 1.8 & $\mathrm{~F}$ & $5 *$ & QUBS & Angling Experiment & Experiment Ended & Released \\
\hline LMB L & 440 & 1250 & 2.7 & M & $4 *$ & QUBS & Angling Experiment & Experiment Ended & Released \\
\hline LMB M & 412 & 1120 & 2.1 & $\mathrm{~F}$ & $4 *$ & QUBS & Angling Experiment & Experiment Ended & Released \\
\hline
\end{tabular}

+ Electrode shift occurred after the validation procedure when the fish was netted repeatedly.

* Value intentionally low because fish released after collection of desired experimental data. 


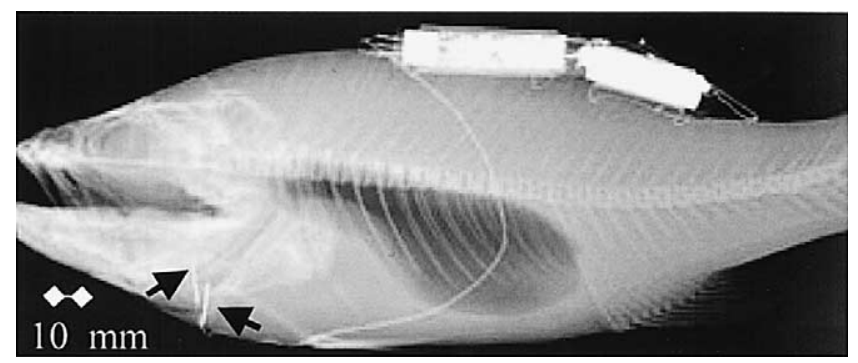

Fig. 2. Radiograph of largemouth bass equipped with an $f \mathrm{H}$ transmitter. The fish (LMB E) was euthanized after developing fungus that did not respond to prophylactic treatment. The electrodes can be seen below the pericardial cavity (denoted by arrows). The transmitter and battery package are evident on the dorsal aspect of the fish.

trimmed. The same procedure was completed on the opposite side of the fish to attach the battery. This part of the procedure typically took no more than three minutes.

Next, the fish was turned over, with the dorsal side down and rested in a sponge sling. Two small incisions $(\sim 3 \mathrm{~mm})$ were made ventro-laterally to the pericardial cavity. For the first surgeries, an additional fish was dissected and used as a guide for the procedure. The electrodes were pushed dorsal-medially through the white muscle until pressure was noted using fingers or small forceps. At this point the electrodes were external but adjacent to the pericardial cavity (Fig. 2). Signals were readily detected when the hydrophone was placed next to the transmitter when the reference electrode was adequately grounded (in water). A drop of cyanoacrylate glue (Loctite, Henkel Inc., Avon, OH) with accelerator was placed superficially to the small incisions immediately prior to suturing them shut (braided silk, 2/0, Ethicon Inc., Somerville, NJ) (Mathews, 1993; Robicsek et al., 1994). The electrodes wires were kinked in several areas to facilitate suturing them to the body of the fish, ensuring that the electrode wires did not interfere with opercular movement. We used between 6 and 8 simple interrupted mattress sutures for each electrode wire. Sutures on the lateral aspect of the fish were intentionally loose to reduce tension associated with flexion. This portion of the procedure requires 10 to 15 minutes to complete with two surgeons. Some fish were exposed to a brief salt bath as a fungal prophylactic to evaluate its effectiveness, whereas other fish were returned to holding tanks or introduced into the enclosures. Mean $( \pm \mathrm{SE})$ transmitter (in water) to body weight ratios were $2.1 \pm 0.2 \%$.

\subsection{Validation}

To verify that the $f \mathrm{H}$ transmitters were indeed detecting individual beats, we attached a Doppler flow probe to the aorta of LMB F. This occurred 11 days after the $f \mathrm{H}$ transmitter was originally attached. Detail on this type of surgical procedure and the instrumentation can be found elsewhere (Cooke et al., 2001; Schreer et al., 2001). Briefly, fish were anesthetized in the same fashion as described above and a flexible silicone cuff-type Doppler flow probe (subminiature $20 \mathrm{MHz}$ piezoelectric transducer: Iowa Doppler Products, Iowa City, IA) was placed around the ventral aorta. Heart rate was monitored and recorded by a hardwired flowmeter (545C-4 Directional Pulsed Doppler Flowmeter: Bioengineering, The University of Iowa, Iowa City, IA) and a digital strip-chart recorder (LabVIEW, Version 4.0.1, National Instruments Corporation, Austin, TX). Heart rate was determined by counting peaks either manually or with an algorithm. The fish was permitted to recover for 24 hours prior to comparing $f \mathrm{H}$ measurements. We monitored the $f \mathrm{H}$ both in real-time and over one minute periods using the Doppler flow probe and the $f \mathrm{H}$ transmitter for a two hour period. Verification was also possible during the attachment of the $f \mathrm{H}$ transmitter by using a fiber optic light to illuminate the area dorsal to the isthmus. The contractions of the heart were clearly visible; correspondence to signals emitted by the $f \mathrm{H}$ transmitter served as further corroboration of correct transmitter function during attachment.

\subsection{Deployment}

We deployed transmitter equipped fish in a range of environments including indoor tanks ( 200 1), a large enclosure in Lake Opinicon $\left(16 \mathrm{~m}^{3}\right)$, and outdoor experimental raceways $\left(16 \mathrm{~m}^{3}\right)$. Water temperature was monitored hourly using temperature recording devices (Hobo Temp Loggers, Onset Inc., Pocasset, MA). Fish were monitored closely following release using visual observations through the air-water interface, snorkeling, and with underwater videography. Videography is the preferred approach as it is non-invasive and permits the recording of behaviors that can later be correlated with $f \mathrm{H}$ patterns. We used a wideangle, low light sensitive underwater color camera (DeepSea Camera and Light Inc., San Diego, CA) in a sealed housing ( $8 \mathrm{~cm}$ diameter, $25 \mathrm{~cm}$ length) to acquire video footage. The fish held in the enclosure in Lake Opinicon were provided with a variety of habitats including undercut banks. One of the fish (LMB D) spent most of the time under the bank permitting the camera to be focused on this individual. We describe three examples of data that can be collected using $f \mathrm{H}$ transmitters; 1) diel activity patterns; 2) behavioral correlates of $f \mathrm{H}$; and 3 ) thermal dependence of $f \mathrm{H}$.

\section{Results}

\subsection{Validation of transmitter function}

The verification procedure that we used illustrated that the $f \mathrm{H}$ transmitter electrodes were positioned properly and that the $f \mathrm{H}$ transmitter was emitting signals triggered by the QRS wave of the ECG at the same time as the peak in blood flood determined by Doppler flow probe measurement (Fig. 3 ). Heart rate from both $f \mathrm{H}$ transmitters and the Doppler flow probe measurements averaged over one minute inter- 


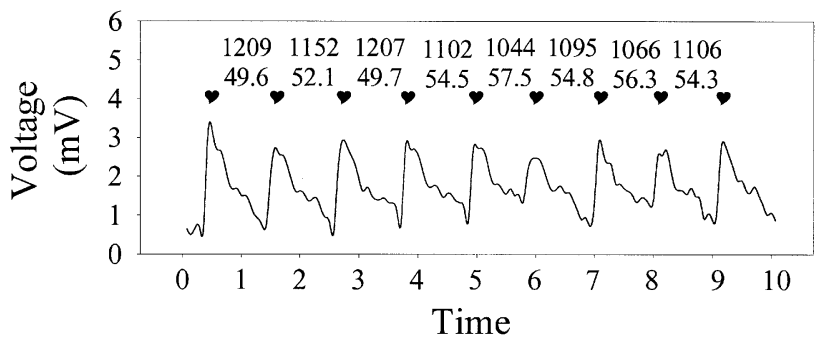

(seconds)

Fig. 3. Real-time comparison of $f \mathrm{H}$ measured using Doppler flow probes and $f \mathrm{H}$ transmitters. A largemouth bass (LMB $\mathrm{F}$ ) was affixed with a Doppler flow probe 11 days after it was equipped with an $f \mathrm{H}$ transmitter. Following recovery $(24 \mathrm{hr}$ ) we monitored $f \mathrm{H}$ using both techniques. The trace represents shifts in voltage resulting from changes in blood flow; each peak represents a single heart beat. The heart symbols indicate when a signal was emitted by the $f \mathrm{H}$ transmitter. The interval between beats in milliseconds (top) and the instantaneous $f \mathrm{H}$ (bottom) are displayed between successive beats.

vals were also strongly correlated $\left(\mathrm{R}^{2}=0.94\right)$ (Fig. 4). The limited variation in this relationship results from differences in how beats per minute are determined and calculated for each method. Manual counting of visualized peaks or a counting algorithm are used to determine $f \mathrm{H}$ from data collected using Doppler probes. Beats per one minute period are thus whole numbers. Telemetrically determined data are based upon the interval between successive beats in milliseconds. These data are then averaged to yield $f \mathrm{H}$ at a finer resolution (we used one decimal place). The disparity among these methods is minor. Both techniques record real-time correlates of $f \mathrm{H}$; variation resulted from differences in resolution and rounding error. Larger time series,
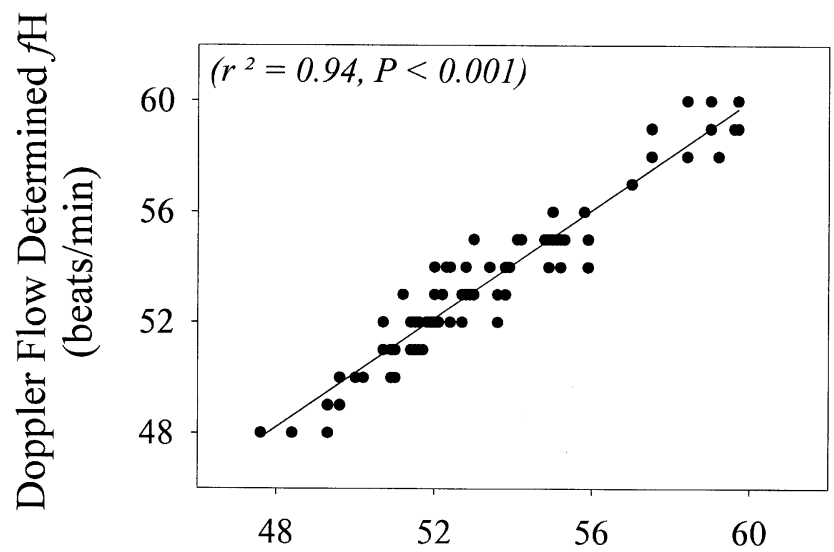

\section{Telemetrically Determined $f \mathrm{H}$ (beats/min)}

Fig. 4. Relationship between mean $f \mathrm{H}$ for 60 second periods measured using Doppler flow probes and $f \mathrm{H}$ transmitters over a $120 \mathrm{~min}$ period. Data are derived from the same fish as in Fig. 3. Linear regression was used to describe the relationship between the two variables. which are possible using both approaches, would yield results that would be virtually indistinguishable.

\subsection{Deployments}

First, we present a series of real time data from a single largemouth bass that was implanted with a transmitter and located using an undercut bank in Lake Opinicon. An underwater video camera was placed adjacent to the bank, and we observed the fish for 15 minutes. In the 15 minute visualized period (Fig. 5), we observed the fish swim out from its cover for no apparent reason, turn around and return within ten seconds. This action resulted in a spike in $f \mathrm{H}$. Approximately 6 minutes later a small $(\sim 100 \mathrm{~mm})$ bluegill, Lepomis macrochirus, swam close to the bass (which remained stationary) resulting in an increase in $f \mathrm{H}$, possibly from excitation. Minutes later a largemouth bass $(\sim 325 \mathrm{~mm})$ swam slowly in front of the undercut bank. The transmitter equipped bass emerged $\sim 10 \mathrm{~cm}$ from the cover and flared its opercula at the smaller bass before again retreating underneath the cover. This also resulted in a heightening of $f \mathrm{H}$.

Although substantial variation is evident on the order of beat to beat, or minute to minute, it is also possible to distill the data through averaging to yield gross patterns of cardiac activity. In this case, we visualized mean hourly $f \mathrm{H}$ over a three day period of stable temperatures $\left(\sim 15^{\circ} \mathrm{C}\right)$ for one specific largemouth bass (LMB D) (Fig. 6). In general, $f \mathrm{H}$ is lower during periods of darkness, with some evidence of crepuscular and diurnal activity.

We also plotted daily noon hour water temperature with daily noon hour mean $f \mathrm{H}$ for three largemouth bass (Fig. 7). Heart rate for largemouth bass was correlated with water temperature during the late spring and early summer between 14 and $26^{\circ} \mathrm{C} . \mathrm{Q}_{10}$ determination indicated that largemouth bass $f \mathrm{H}$ exhibited reasonable thermal conformity $\left(\mathrm{Q}_{10} 14-26^{\circ} \mathrm{C}, \sim 1.3\right)$.

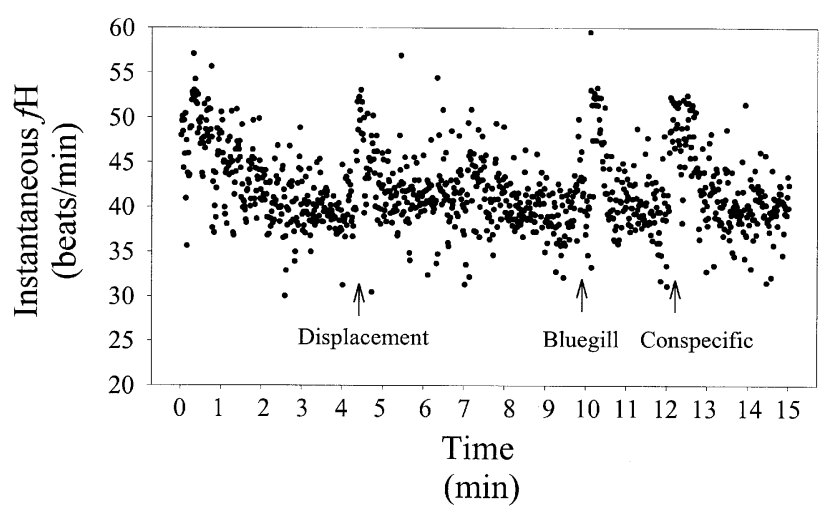

Fig. 5. Cardiac response of largemouth bass to different behaviors and social interactions. Data are real time over a fifteen minute period for LMB D. Using videography, several activities and behaviors are noted. Displacement indicated a movement by the fish, "bluegill" indicated when a small bluegill swam by, and "conspecific" indicated when a smaller largemouth bass swam by slowly resulting in a frontal display. The fish was in a large enclosure in Lake Opinicon, Ontario residing beneath an undercut bank. 


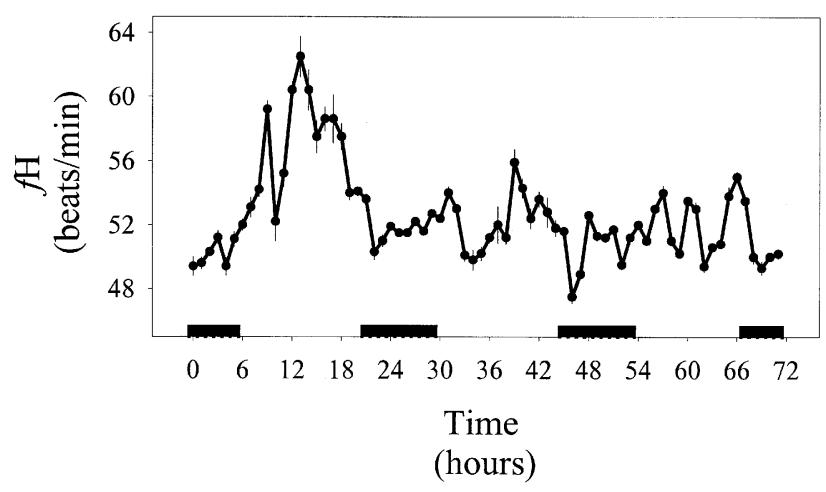

Fig. 6. Diel patterns in largemouth bass cardiac activity determined using $f \mathrm{H}$ transmitters. Heart rate data represent hourly means and standard errors for LMB D during a 72 hour period. "0" hours represents midnight. Black bars beneath the trace indicate periods of darkness (after sunset to before sunrise). The fish was in a large enclosure in Lake Opinicon, Ontario.

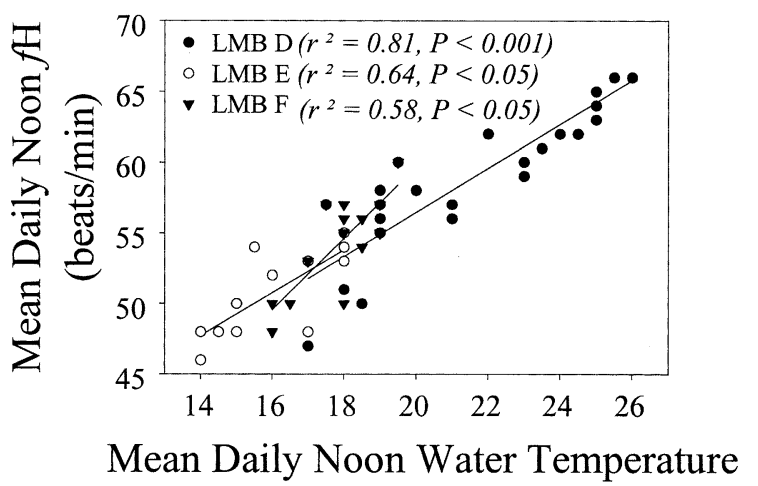

$\left({ }^{\circ} \mathrm{C}\right)$

Figure 7. Temperature dependence of telemetrically determined $f \mathrm{H}$ in largemouth bass. Mean daily water temperature for the 12:00 to 13:00 period and mean daily $f \mathrm{H}$ for the same period are plotted. Linear regression was used to describe the relationships for each of three largemouth bass (LMB D,E,F) held in a large enclosure in Lake Opinicon, Ontario.

\section{Discussion}

Transmitter attachment techniques have varied depending upon the species of fish and the characteristics of the transmitter. Other examples of external attachment techniques include using a foam saddle and sutures to secure a $f \mathrm{H}$ transmitter to the medial anterio-dorsal surface of northern pike (Armstrong et al., 1989) and a detailed anterioventral harness technique for Atlantic cod, Gadus morhua (Claireaux and Lefrançois, 1998). Using a ventral harness was not possible for largemouth bass because they frequently sit on or close to the bottom. Lucas (1992) details a transmitter configuration for intragastric implantation in Atlantic salmon, Salmo salar. His procedure only required 1-2 minutes but this system is not appropriate for long term monitoring if fish are to resume feeding. The use of intraperitoneal implantations of transmitters and subcutaneous electrodes (as in Rabben and Furevik, 1993) is perhaps the best approach, as they do not create additional drag or opportunity for fouling, but this approach requires larger fish or smaller transmitters.
The customization of the transmitter and attachment technique that we described above has proven to be an effective approach for monitoring the long-term $f \mathrm{H}$ patterns of free-swimming largemouth bass. Only one study has monitored $f \mathrm{H}$ for an extended period; transmitters were implanted in a large halibut, Hippoglossus hippoglossus, $(\sim 5.2 \mathrm{~kg})$ for 4 months in an aquaculture facility (Rabben and Furevik, 1993). Using the technique that we described, we were able to collect continuous records for a mean $( \pm \mathrm{SE})$ of $8 \pm 2$ days, but as long as 32 days on one fish. Excluding fish that were part of experiments that intentionally terminated after several days, the mean ( \pm SE) duration was $13 \pm 3$ days. We suspect, however, that 32 days is approaching the limit for deployment with external apparatus. The enclosures that we used had a moderate amount of aquatic vegetation and complex structure, and on occasion, some fish were observed trailing vegetation from the transmitter. In practice, if the fish were at complete liberty, the transmitters may have become fouled by aquatic vegetation or other debris. Furthermore, the braided silk sutures used to immobilize the external electrode wires would eventually be rejected as part of the active healing process. To ameliorate the concerns from fouling, healing and electrode shifting, we have experimented unsuccessfully with internal (subcutaneous and intramuscuscular) placement of several $\mathrm{cm}$ of electrode wire.

The design of the electrodes, electrode placement and electrode stabilization are the most important and difficult aspects of using $f \mathrm{H}$ telemetry. The electrodes need to be positioned close to the pericardial cavity so that they can detect voltage potentials, but it is important that the integrity of the cavity is not violated. Farrell et al. (1988) report that violations of the pericardial membrane (pericardium) in rainbow trout, Oncorhynchus mykiss, resulted in altered cardiac performance. Although most studies provide insufficient detail to determine the exact location of the electrodes to ascertain if they violated the pericardial membrane, several studies have reported that such violations were in fact necessary to detect $f \mathrm{H}$ (e.g., Scharold and Gruber, 1991; Claireaux et al., 1995; Anderson et al., 1998). Post-mortem dissections on the first three fish that we implanted with $f \mathrm{H}$ transmitters revealed that electrodes were ventral to the pericardial cavity and were touching, but did not violate the pericardial membrane.

Correct electrode design is essential for detecting changes in voltage. In all cases, the electrode and electrode wires should be insulated for all but the very distal end of the electrode. We experimented with bare stainless steel wire, rigid stainless steel bars, and gold bars. Our best results were obtained using small electronic components plated in gold that provided a blunt detection surface and sufficient rigidity and surface area to facilitate positioning with forceps. It is also important that if the electrodes are introduced externally, as in our case, that the incision site and the region surrounding the electrode wires must be as 
water tight as possible. If water enters the region containing the electrodes, changes in tissue external to the pericardial cavity may occur that will impair or alter signal detection. These tissue changes may occur over time as has been noted by Beddow and McKinley (1998) using gold electrodes in axial musculature.

After transmitter deployments ranging from 3 days to 32 days, fish were recaptured if there were erratic and erroneous signals logged by the receiver or if visual observation (snorkeling or underwater videography) indicated that the electrodes had become dislodged. Several fish developed fungus, but this was later ameliorated with salt immersion baths. An advantage of the external attachment technique that we employed was that the transmitter could be removed easily without euthanizing the fish. To remove the transmitter after collecting desired data or after loss of signals, fish were anesthetized and the entire transmitter apparatus was removed. We closed the two small electrode incisions with one suture each and provided a salt bath prior to release in the natural environment. The fish all appeared healthy, and we have full confidence that these fish resumed normal behavior. One fish was observed $\sim 24$ hours after release by a snorkeler, behaving normally, seeking cover under a dock. Recovering the transmitter permits redeployment following refurbishing (change of battery if required) and in our case, permitted us to release trophy size fish that had provided us with extensive data sets, thus eliminating some concerns regarding fish population impacts or animal welfare issues.

Collectively, our results from initial deployments suggest that $f \mathrm{H}$ transmitters are effective for monitoring physiological responses to a variety of conditions. For example, social interactions and high-resolution assessments (seconds) of the relationship between swimming activity and $f \mathrm{H}$ are poorly understood. Our data on social interactions highlight the potential range of biological factors that may contribute to the variability of $f \mathrm{H}$ in the field. The diel activity patterns we observed were consistent with measures of largemouth bass locomotory activity in laboratory environments (Davis, 1964; Reynolds and Casterlin, 1976) and in free-swimming fish in the field (Demers et al., 1996). Based upon the strong tendency towards cardiac frequency modulation for largemouth bass and the data indicating diel patterns in cardiac activity, we suspect that locomotory activity and $f \mathrm{H}$ are strongly coupled in this species, as observed elsewhere (i.e., Sureau and Lagardère, 1991). Finally, the relationship between water temperature and $f \mathrm{H}$ we observed was consistent with previously published data on the temperature dependence of $f \mathrm{H}$ in the congeneric smallmouth bass, Micropterus dolomieu, (Schreer et al., 2001; Schreer and Cooke, in press) and forthcoming data on largemouth bass (Cooke, unpublished data). The temperature dependence of cardiac performance in many fish species is well known. Heart rate increases with temperature due to increased membrane permeability of the pacemaker fibres and change in the vagal tone (Satchell, 1991).

\subsection{Conclusion}

The intention of this paper was to execute a preliminary study on the influence of various environmental factors on $f \mathrm{H}$ of largemouth bass in a semi-natural environment. Collectively, these examples from initial deployments of $f \mathrm{H}$ transmitters illustrate the range of uses for remotely collected $f \mathrm{H}$ data. The examples that we provide do not require estimates of oxygen consumption to be relevant contributions to science. Alone, these data can be used to examine patterns and trends in $\mathrm{fH}$ that clearly have an important, but so far, undetermined energetic cost. Furthermore, because $f \mathrm{H}$ frequently increases with increased locomotory activity (at least in cardiac frequency modulating species), it is reasonable to use $f \mathrm{H}$ as a behavioral indicator. In aquaculture facilities, $f \mathrm{H}$ can also be used as a correlate for animal welfare (Rabben and Furevik, 1993). Using the techniques that we describe in this paper, researchers may generate testable hypotheses for basic and applied ecological and environmental physiology. To date, studies have been largely restricted to only a few fish species (Atlantic cod, European sea bass, Dicentrarchus labrax, sole, Solea solea, northern pike, lemon sharks, Negaprion brevirostris, and salmonids). This detailed methodology will permit studies of most fish with fusiform body forms to attach these transmitters. Researchers working on fish with other body shapes can integrate the most relevant aspects of our methodology with those of others methodologies to develop the most appropriate $f \mathrm{H}$ transmitter attachment technique for their desired application.

\section{Acknowledgements}

Kate Deters assisted with surgical procedures and Dr. Ken Ostrand assisted with fish collection. We also thank the staff of the Queen's University Biological Station (particularly Frank Phelan) for facilitating this research and Dr. Dale Webber and Vemco Inc. for providing technical guidance during this project. We are also grateful to Dr. Martyn Lucas and an anonymous reviewer for providing valuable comments on the manuscript. These procedures were developed under the guidance of the Illinois Office of Laboratory Animal Research and Queen's University Animal Care Committee. Financial assistance for this project was provided by the Illinois Natural History Survey, Illinois Department of Natural Resources, the University of Illinois, and the Natural Sciences and Engineering Research Council of Canada.

\section{References}

Anderson, W.G., Booth, R., Beddow, T.A., McKinley, R.S., Finstad, B., Økland, F., Scruton, D., 1998. Remote monitoring of heart rate as a 
measure of recovery in angled Atlantic salmon, Salmo salar (L.). Hydrobiologia 371/372, 233-240.

Armstrong, J.D., 1998. Relationships between heart rate and metabolic rate of pike: integration of existing data. J. Fish Biol. 52, 362-368.

Armstrong, J.D., Lucas, M.C., Priede, I.G., De Vera, L., 1989. An acoustic telemetry system for monitoring the heart rate of pike, Esox lucius L., and other fish in their natural environment. J. Exp. Biol. 143, 549-552.

Beddow, T.A., McKinley, R.S., 1998. Effects of thermal environment on electromyographical signals obtained from Atlantic salmon (Salmo salar L.) during forced swimming. Hydrobiologia 371/372, 225-232.

Claireaux, G., Webber, D.M., Kerr, S.R., Boutilier, R.G., 1995. Physiology and behaviour of free-swimming Atlantic cod (Gadus morhua) facing fluctuating temperature conditions. J. Exp. Biol. 198, 49-60.

Claireaux, G., Lefrançois, C., 1998. A method for the external attachment of acoustic tags on roundfish. Hydrobiologia 371/372, 113-116.

Cooke, S.J., Philipp, D.P., Dunmall, K.M., Schreer, J.F., 2001. The influence of terminal tackle on injury, handling time, and cardiac disturbance of rock bass. N. Am. J. Fish. Manage. 21, 265-274.

Davis, R.E., 1964. Daily "predawn" peak of locomotion in fish. Anim. Behav. 12, 272-283.

Demers, E., McKinley, R.S., Weatherley, A.H., McQueen, D.J., 1996. Activity patterns of largemouth and smallmouth bass determined with electromyogram biotelemetry. Trans. Am. Fish. Soc. 125, 434-439.

Farrell, A.P., 1991. From hagfish to tuna: a perspective on cardiac function in fish. Physiol. Zool. 64, 1137-1164.

Farrell, A.P., Johansen, J.A., Graham, M.S., 1988. The role of the pericardium in cardiac performance of the trout (Salmo gairdneri. Physiol. Zool. 61, 213-221.

Lefrançois, C., Claireaux, G., Lagardère, J.-P., 1998. Heart rate telemetry to study environmental influences on fish metabolic expenditure. Hydrobiologia 371/372, 215-224.

Lucas, M.C., Priede, I.G., Armstrong, J.D., Gindy, A.N.Z., De Vera, L., 1991. Direct measurement of metabolism, activity and feeding behaviour of pike. Esox lucius L., in the wild by the use of heart rate telemetry. J. Fish Biol. 39, 325-345.

Lucas, M.C., 1992. An electrode design for use with intragastric heart rate transmitters in Atlantic salmon (Salmo salar L.) and other fish. In:
Priede, I.G., Swift, S.M (Eds.), Wildlife telemetry - remote monitoring and tracking of animals. Ellis Horwood, New York.

Mathews, S.C., 1993. Tissue bonding: the bacteriological properties of a commercially-available cyanoacrylate adhesive. British J. Biomed. Sci. $50,17-20$.

Priede, I.G., 1983. Heart rate telemetry from fish in the natural environment. Comp. Biochem. Physiol. 6A, 515-524.

Rabben, H., Furevik, D.M., 1993. Application of heart rate transmitters in behaviour studies on Atlantic halibut (Hippoglossus hippoglossus. Aquac. Eng. 12, 129-140.

Reynolds, W.W., Casterlin, M.E., 1976. Activity rhythms and light intensity preferences of Micropterus salmoides and M. dolomieu. Trans. Am. Fish. Soc. 105, 400-403.

Robicsek, F., Rielly, J.P., Marroum, M.C., 1994. The use of cyanoacrylate adhesive (Krazy Glue) in cardiac surgery. J. Cardiac Surg. 9, 353-356.

Satchell, G.H., 1991. Physiology and form of fish circulation. Cambridge University Press, Cambridge, UK.

Schreer, J.F., Cooke, S.J., McKinley, R.S., 2001. Cardiac response to variable forced exercise at different temperatures: an angling simulation for smallmouth bass. Trans. Am. Fish. Soc. 130, 783-795.

Schreer, J.F., Cooke, S.J., in press. Behavioral and physiological responses of smallmouth bass to a dynamic thermal environment. Am. Fish. Soc. Symp.

Scharold, J., Gruber, S.H., 1991. Telemetered heart rate as a measure of metabolic rate in the lemon shark, Negaprion brevirostris. Copeia, 942-953.

Sureau, D., Lagardère, J.-P., 1991. Coupling of heart rate and locomotor activity in sole, Solea solea (L.), and bass, Dicentrarchus labrax (L.), in their natural environment by using ultrasonic telemetry. J. Fish Biol. 38, 399-405.

Thorarensen, H., Gallaugher, P.E., Farrell, A.P., 1996. The limitations of heart rate as a predictor of metabolic rate in fish. J. Fish Biol. 49, 226-236.

VEMCO, 1995. V16H-4HR heart rate transmitter operating manual 95-0630. Vemco Inc. Shad Bay, Nova Scotia. 